\title{
VIABILIDADE DO GOOGLE MEET EM AULAS REMOTAS
}

Tiago Bezerra Marinho' ${ }^{1}$ - tiagobezerramarinho@gmail.com

Rafael Souza Lemos ${ }^{1}$ - rafaellemostelecom@gmail.com

Abrahão Lucas Barboza Nunes² - abras.lucas1536@ gmail.com

Antônio César Bezerra Silva² - cesarbezerra131@gmail.com

Daniel do Nascimento e Sá Cavalcante ${ }^{2}$ - danielsacavalcante @ gmail.com

${ }^{1}$ Instituto Federal do Ceará, Avenida treze de maio - 2081, 60040215 - Fortaleza - Ceará

${ }^{2}$ Instituto Federal do Ceará, Rua Pedro Bezerra de Menezes - 387 - Jaguaribe - Ceará

Resumo: Com a pandemia de Covid-19, em 2020 o mundo teve que se adaptar e lidar com um "novo normal". Na área de educação não foi diferente, e várias instituições de ensino ao redor do mundo tiveram que mudar a forma como desenvolviam suas atividades. $O$ ensino no formato de Educação a Distância (a EaD) tem uma estrutura bem definida e, para ele, estudantes precisam estar preparados, e docentes precisam estar capacitados para o escopo. Não havendo tempo ou a infraestrutura necessária para se adaptar à EaD, docentes têm optado por aulas remotas, utilizando ferramentas como Skype, Zoom, Discord, YouTube, Instagram e Google Meet. Este trabalho apresenta uma análise de viabilidade do uso do Google Meet como ferramenta para aulas remotas, mostrando suas características, vantagens e desvantagens enquanto plataforma de comunicação de áudio e vídeo sendo usada para fins didáticos. Desenvolvemos um ciclo de aulas e eventos on-line, pelo Google Meet, e em seguida aplicamos um questionário semiestruturado com 77 participantes. Como resultados, detectamos uma alta satisfação dos usuários, onde $89,61 \%$ avaliam a interface como amigável, 96,10\% consideram o recurso de gravação da aula útil e 88,31\% consideram o compartilhamento de tela um recurso importante. Além disso, ao compararmos com outras ferramentas, o Google Meet foi o melhor qualificado com 97,4\% de satisfação, seguido pelo YouTube Live com 67,53\%.

Palavras-chave: Google Meet. Ensino Remoto. Aulas remotas. Educação a Distância. Ensino a Distância.

\section{INTRODUÇÃO}

Com a chegada do ano de 2020, o mundo se deparou com um enorme obstáculo para a vivência normal e para o bem estar da população, a pandemia do Covid-19. Tendo sua origem na China, o vírus chegou ao Brasil e teve seu primeiro caso confirmado em 26 de fevereiro. Dado o rápido espalhamento do vírus pelo país, em 11 de março ocorreu a primeira suspensão de aulas da rede pública e da rede privada, marcando os primeiros passos de enfrentamento à pandemia no Brasil (G1, 2020).

Durante a pandemia, podemos notar que o sistema educacional, em sua maioria, possui diversas vulnerabilidades e não está preparado para esse tipo de problema. Em muitas instituições de ensino, foi então instituído um sistema de ensino remoto emergencial, havendo muitas dificuldades de adaptação por parte de docentes e discentes. De acordo com Bozkurt e Sharma (2020), a EaD deve fornecer agilidade, responsabilidade, flexibilidade e possibilidade de escolha aos alunos, o que requer um planejamento e projeto para um resultado totalmente eficaz, diferentemente do ensino remoto emergencial, pois esse se trata de uma solução 
temporária para esse tipo de situação. Tendo em vista esse cenário, a utilização de ferramentas que auxiliem na aplicação do ensino remoto se mostra fundamental para que possa ser ministrado um conteúdo com um mínimo de qualidade para os alunos.

Vale destacar que muitos conteúdos preveem aulas práticas em laboratórios, as quais, no momento, não podem ser executadas presencialmente, o que demanda a aplicação de novos métodos de ensino que proporcionem uma experiência similar à de sala de aula. Entretanto, muitos educadores ainda não estão capacitados para implementar essas novas metodologias (Bradley et al., 2020). Assim, podemos afirmar que o ensino a distância (o EaD) não se resume apenas a usar ferramentas on-line para transmitir aulas, mas demanda requisitos adicionais, como a capacitação de docentes e discentes.

Para Kenski (2017), os alunos devem ter a opção de escolha entre as modalidades a distância ou presencial sem que isto gere consequências negativas para sua formação. Portanto, para que o ensino não seja interrompido, desde o ensino básico ao superior, além das formações e capacitações profissionais de que o mercado de trabalho necessita, faz-se necessária a adaptação ao ensino remoto.

Visando atender à demanda por tecnologias que sirvam ao ensino remoto, algumas empresas dispõem de ferramentas gratuitas, tanto para computadores quanto para smartphones, que podem ser utilizadas como uma "sala de aula virtual", dentre as quais destacamos o Skype, o Zoom e o Google Meet. Além dessas, outras também vêm sendo utilizadas, como Instagram Live, YouTube Live e o Discord.

Neste trabalho, avaliamos o Google Meet como uma ferramenta de ensino remoto e mostramos suas diversas vantagens e desvantagens neste contexto. Apresentamos, ainda, alguns motivos pelos quais consideramos o Google Meet superior às outras ferramentas considerando diversos parâmetros.

\section{FUNDAMENTAÇÃO TEÓRICA}

Scherer e Brito (2014) destacam que a EaD possibilita o acesso à educação e à formação àqueles que não podem estar presencialmente em uma sala de aula, conforme é requerido na metodologia tradicional. Chilton e Wendy (2017) afirmam que as tecnologias móveis vêm se tornando cada vez mais frequentes nos ambientes de ensino superior e têm o potencial de impactar o processo de aprendizagem, mas Costa (2017) relembra que a EaD no Brasil é anterior à popularização do acesso à Internet, tendo iniciado muitas décadas antes, por meio de outras ferramentas de comunicação.

Vagarinho (2018) ressalta que o EaD é bastante amplo e não pode ser definido simplesmente como o antônimo do ensino presencial. Existem algumas características e subcaracterísticas que podem distinguir ou agrupar os significados de distance learning, $e$ learning e m-learning. Dentre elas, é possível citar a tecnologia (ferramentas e procedimentos), o curso (metodologia e objetivos), nível de acessibilidade, comunicação e outros que formam uma estrutura ampla com definições distintas entre termos.

Fonseca e Neto (2017) trazem à tona a importância da interação, da dedicação e do interesse do aluno em não apenas ouvir e repetir o ensino transmitido pelo professor, mas sim investigar e ter, além da tecnologia, o educador como um apoio para desenvolver a sua autonomia em adquirir conhecimento, seja este um discente do ensino básico ou superior.

Pôr em prática uma nova modalidade de ensino, retirando parcialmente ou por completo a metodologia da sala de aula presencial, requer um esforço que vai muito além daquele de os docentes conhecerem as ferramentas necessárias e planejarem a estrutura do ensino realizado a distância. Segundo Kenski (2017), os programas de EaD devem atender os alunos com o 
uso de diversos meios tecnológicos disponíveis, desde a impressão do material a ser utilizado até a disponibilização de plataformas e serviços digitais que possibilitam o ensino.

Devido à urgência de adaptação demandada pela pandemia e à impossibilidade de uma adaptação completa ao $\mathrm{EaD}$, seja por falta de uma plataforma completa, ou por falta de formação dos professores, ou por falta de infraestrutura dos alunos, vem se destacando o ensino no formato remoto, que usa algumas ferramentas de EaD mas não pode ser classificado como EaD em sua plenitude.

Segundo Charles et al. (2020), ao contrário das experiências planejadas desde o início e projetadas para serem on-line, o Ensino Remoto de Emergência é uma mudança temporária para um modo de ensino alternativo devido a circunstâncias de crise. Envolve o uso de soluções totalmente remotas para o ensino que em outros momentos seria ministrado presencialmente ou como curso híbrido e que retornará a esses formatos assim que a crise ou emergência diminuir ou acabar. O objetivo nessas circunstâncias não é recriar um sistema educacional robusto, mas fornecer acesso temporário a suportes e conteúdos educacionais de maneira rápida, fácil de configurar e confiável, durante uma emergência ou crise.

Ghazal et al. (2015) afirmam que a comunicação no modelo EaD é implementada por dois métodos diferentes: o método assíncrono e o síncrono. O modelo síncrono permite que alunos e professores se comuniquem ao mesmo tempo, apesar dos diferentes locais. Já o modelo assíncrono não requer que o aluno e o professor se comuniquem em tempo real. Isto fornece aos alunos a flexibilidade de completar suas aprendizagens baseado em sua própria velocidade e em seu próprio tempo. Murata e Fujimoto (2019) explicam que as aulas assíncronas são gravadas em formato de áudio e/ou vídeo e postadas em plataformas on-line, enquanto as aulas síncronas utilizam ferramentas de videoconferência.

Alguns autores vêm aplicando aulas remotas no ensino. Maia e Castro Filho (2017) avaliaram o uso do Skype, Facebook e WhatsApp na formação de professores que ensinam Matemática. Allsop et al. (2020) usam videoconferências para ministrar sessões de ensino para estudantes de medicina durante estágio clínico. Chick et al. (2020) discutem soluções para manter a educação cirúrgica de estudantes de medicina residentes na época de isolamento provocado pelo Covid-19, propondo teleconferências e simulação de procedimentos on-line. Os autores afirmam que, embora esses métodos não sejam um substituto para o aprendizado prático, é necessário inovar para manter a aprendizagem constante durante esse período. Mustafa (2020) analisa o impacto do YouTube, do Skype e do WhatsApp em relação à melhoria do aprendizado de inglês como língua estrangeira na habilidade de fala dos estudantes, concluindo que as redes sociais possuem um grande impacto positivo no desenvolvimento da fala para esses estudantes.

\section{METODOLOGIA}

O presente trabalho constitui um estudo analítico da plataforma de reuniões do Google, o Google Meet, no contexto em que é usada como uma ferramenta para aulas remotas. Além disso, também destacamos as principais características, vantagens e desvantagens em relação a seu uso enquanto plataforma de comunicação de áudio e vídeo para fins didáticos. Desenvolvemos um ciclo de aulas e eventos on-line, pelo Google Meet, e em seguida aplicamos um questionário semiestruturado com 77 participantes.

\subsection{Descrição da plataforma}

Nesta seção apresentamos com mais detalhes a plataforma Google Meet, desde suas características mais básicas até algumas extensões que potencializam o uso desta ferramenta. 
O Google Meet é uma ferramenta gratuita da empresa Google, que permite chamada de vídeo, voz e compartilhamento de tela em grupo (AL-FRAIHAT et al., 2020). Em sua versão gratuita, ele atende a poucos usuários e limita a duração das videoconferências. Contudo, durante a pandemia do Covid-19, a empresa disponibilizou a versão premium com acesso gratuito para seu público por um tempo limitado, ampliando para 250 a capacidade de pessoas em uma videochamada e tornando o tempo da chamada ilimitado. Essa decisão impulsionou o uso da ferramenta nas atividades de trabalho remoto, e a plataforma obteve em torno de 3 milhões de usuários novos por dia durante os primeiros meses de pandemia (TECNOBLOG, 2020).

$\mathrm{O}$ acesso à ferramenta pode ser feito de duas formas: via web, bastando que o usuário clique em um link gerado na criação da videoconferência; ou via aplicativo, o qual pode ser instalado gratuitamente em várias marcas de smartphones. Aqueles que fazem parte da mesma instituição que o anfitrião da conferência (aquele que a criou) não precisam de permissão para entrar na chamada, bastando estarem conectados na conta de e-mail institucional e terem acesso ao link ou ao código de acesso. Já aqueles que não fazem parte da mesma instituição precisam ter sua solicitação de entrada aprovada pelo anfitrião. $\mathrm{O}$ anfitrião dispõe, ainda, de algumas permissões adicionais, como a possibilidade de desativar o microfone de um convidado e de remover participantes inconvenientes.

$\mathrm{Na}$ Figura 1, mostramos uma captura de tela durante uma aula, com campos enumerados de 1 a 5, onde: (1) representa os "Detalhes da reunião", onde podemos obter o link da reunião e onde são exibidos anexos referentes ao Google Agenda; (2) apresenta três ícones que representam, respectivamente, as opções de ligar/desligar o microfone, encerrar a chamada e ligar/desligar a câmera; (3) mostra a opção "Apresentar agora", a partir da qual o usuário pode compartilhar com os demais participantes sua tela inteira, uma janela ou uma guia do navegador; ao clicar nos três pontos, à direita, podemos escolher dentre as opções: gravar a reunião (disponível quando o anfitrião tem conta $G$ Suite), alterar o layout das exibições e entrar no modo tela cheia; (4) mostra os participantes presentes na aula; (5) abre o chat.

Figura 1: Captura de tela durante uma aula.

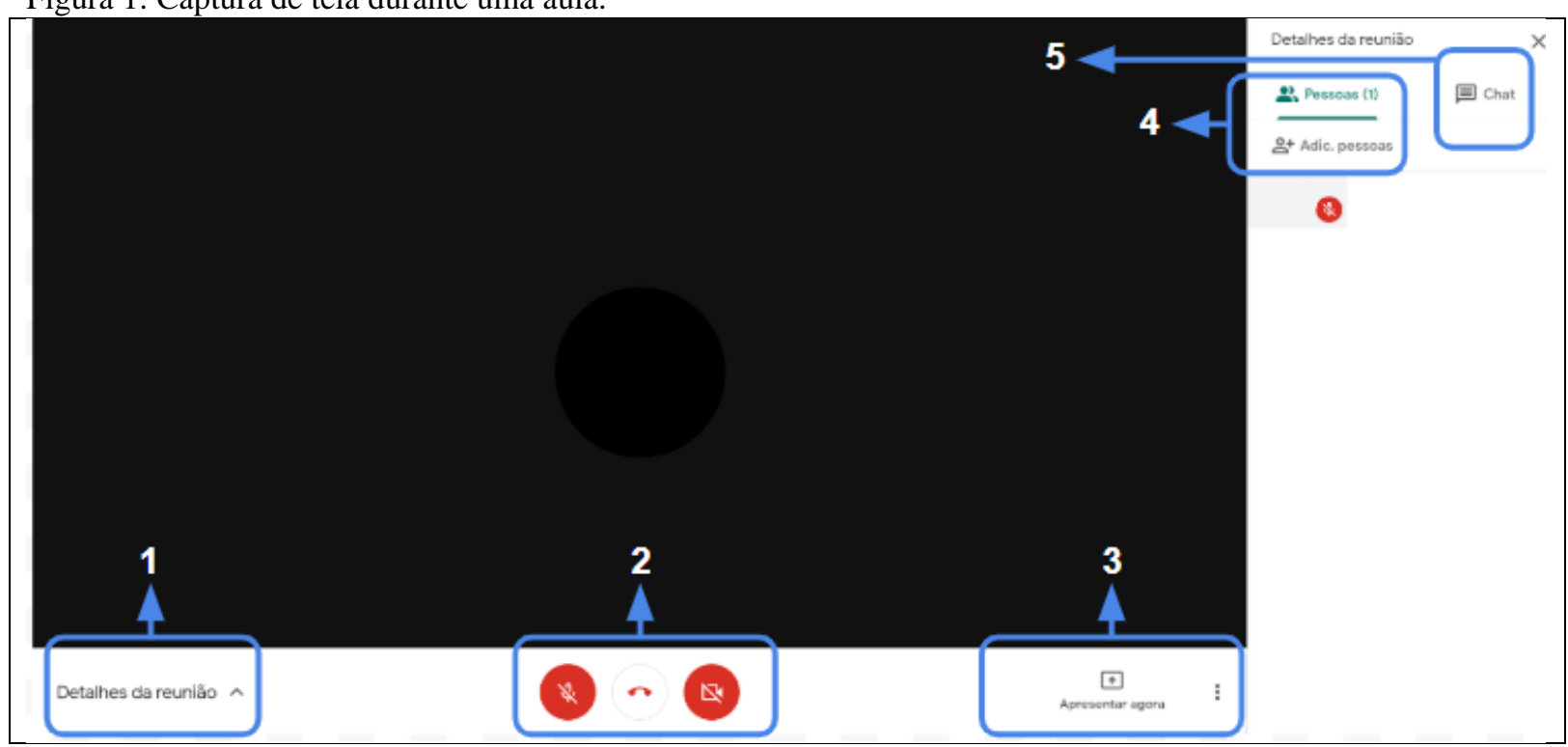

\subsection{Extensões do Google Meet}

Existem algumas extensões que podem potencializar o uso do Google Meet quando o usuário usa o navegador Google Chrome. 


\begin{tabular}{|l|l|}
\hline Extensão & Funcionalidades \\
\hline Grid View & $\begin{array}{l}\text { Permite a exibição dos participantes em forma de grade, incluindo seu nome e } \\
\text { foto. É possível destacar quem estiver falando, ocultar participantes sem } \\
\text { câmera e incluir o próprio vídeo. }\end{array}$ \\
\hline $\begin{array}{l}\text { Nod }- \\
\text { Reactions }\end{array}$ & $\begin{array}{l}\text { Permite o envio de feedback imediato para o anfitrião por meio de reações dos } \\
\text { participantes. }\end{array}$ \\
\hline Attendance & Gera lista de presença dos participantes da reunião em formatos .xls e .html. \\
\hline Web Paint & $\begin{array}{l}\text { Disponibiliza ferramentas de desenho que permitem o apresentador selecionar, } \\
\text { pintar e escrever textos na página web compartilhada. }\end{array}$ \\
\hline
\end{tabular}

Quadro 1 - Extensões e suas funcionalidades.

\section{RESULTADOS E DISCUSSÃO}

Para validar nossa hipótese, aplicamos uma pesquisa semiestruturada com 77 pessoas que participaram, entre os meses de março e julho de 2020, de diversos eventos realizados por meio do Google Meet com o apoio do IFCE Campus Jaguaribe (Figura 2). Os números mostram quantos respondentes participaram de cada atividade. A soma de todos ultrapassa os 77 porque algumas pessoas participaram de dois ou mais eventos.

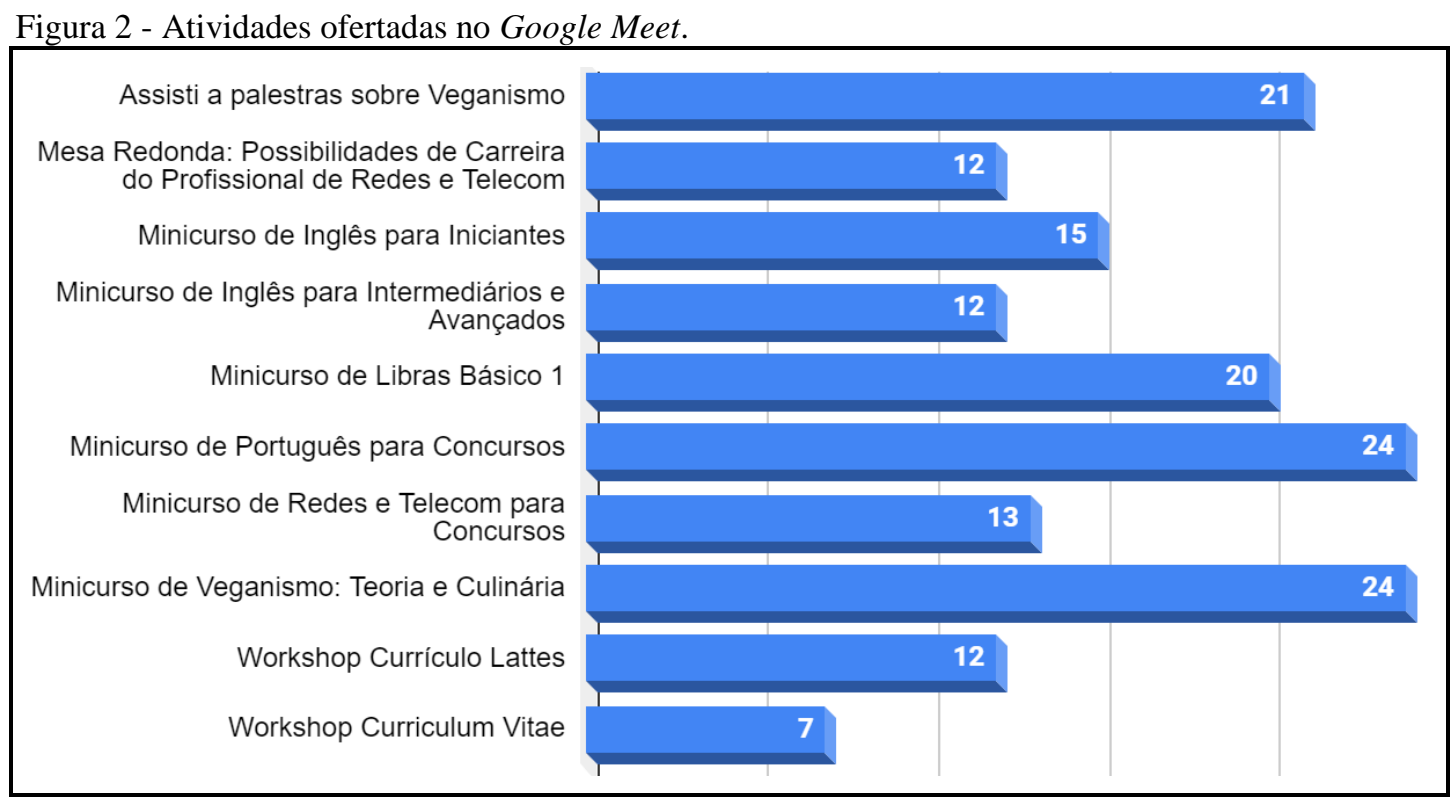

Desta forma, é possível analisar a versatilidade da plataforma para o EaD de atividades de curta duração, podendo ser utilizado para aulas que necessitam de funções específicas, como: o "Minicurso de Inglês para Intermediários e Avançados", que focava a conversação em grupo na língua inglesa e necessitava prioritariamente do microfone; os workshops de Currículo Lattes e de Curriculum Vitae, que, por se tratarem de treinamentos com práticas de como fazer um currículo, necessitaram do compartilhamento de tela do professor para os alunos; e também a função da câmera que permitiu a realização do "Minicurso de Libras Básico 1", um idioma que tem como base a língua de sinais, sendo inviável a realização via mensagens de texto ou voz.

Dos respondentes, a maior parte são jovens entre 19 e 25 anos (41,6\%) e entre 26 e 40 anos $(35,1 \%)$. A baixa participação de menores de 18 anos $(6,5 \%)$ pode estar associada à falta 
de interesse nos temas abordados nos eventos. A tímida participação de pessoas entre 41 e 59 anos $(14,3 \%)$ e acima de 60 anos $(2,6 \%)$ pode ser devido a dificuldades de manuseio de computadores e smartphones.

Mapeamos os respondentes quanto aos dispositivos e métodos de conexão à Internet utilizados para participação nos eventos. Com relação aos dispositivos utilizados, constatamos que não houve prevalência significativa de um meio, com 51,9\% dos respondentes tendo acessado via aplicativo no celular e $46,8 \%$ tendo usado o computador; apenas $1,3 \%$ variou entre os dois meios. Com relação à conexão com a Internet utilizada, a grande maioria usou o Wi-Fi $(90,1 \%)$, enquanto alguns utilizaram o cabo Ethernet diretamente conectado ao computador $(6,5 \%)$, enquanto apenas um $(1,3 \%)$ revezou entre esses dois métodos, e outro $(1,3 \%)$ usou os dados móveis pelo smartphone.

Pedimos para os participantes avaliarem algumas características do Google Meet, tais como a estabilidade da conexão, a interface, a utilidade da gravação, do chat e do compartilhamento de tela, a facilidade de entrada na conferência e a preferência por participação por voz. Na Figura 3, apresentamos as respostas dos participantes, onde constatamos que mais de $77 \%$ dos respondentes avaliam de forma muito positiva a interface, a gravação, o compartilhamento de tela, o chat e a facilidade de entrada na conferência, com destaque para a utilidade da gravação da conferência, com a qual $96 \%$ afirmaram concordar plenamente. O critério com menor aprovação foi a estabilidade da conexão, para o qual quase $60 \%$ afirmaram concordar plenamente, mas 35\% relataram ter ressalvas, o que provavelmente é explicável pelas limitadas taxas de transferência de boa parte dos usuários, especialmente quando visto que a maioria dos usuários utilizavam o Wi-Fi para acessar a aula. Por fim, podemos notar que as opiniões se dividem mais em relação à preferência do uso do recurso de voz, onde $31 \%$ concorda plenamente que prefere usá-lo, enquanto os demais divergem dessa opinião.

Figura 3 - Satisfação dos participantes com relação a alguns recursos do Google Meet.

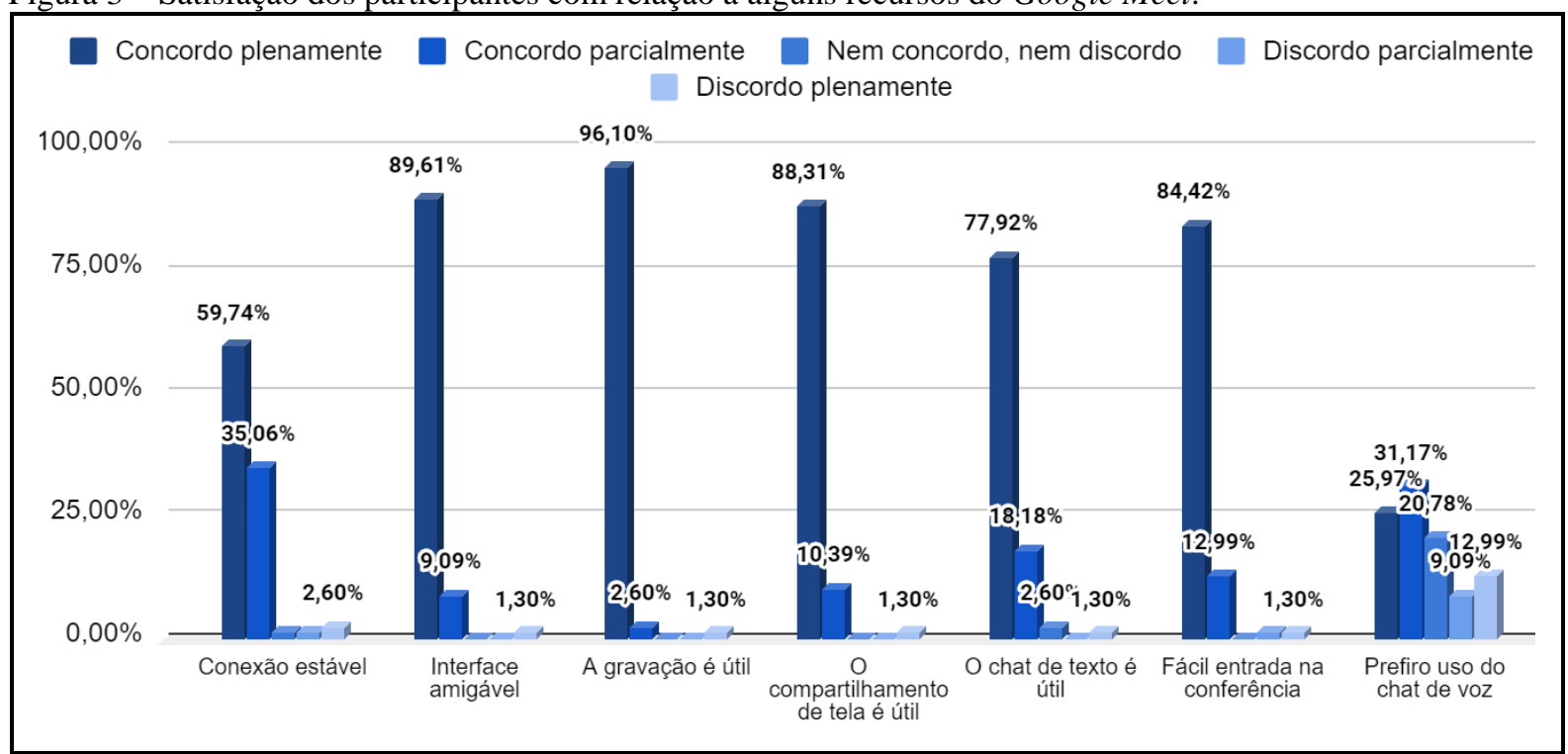

Visando conhecer o nível de interesse e disposição dos usuários para participar de diferentes tipos de cursos usando o Google Meet, questionamo-lhes se estariam dispostos a participar desde eventos curtos (como palestras) até cursar uma disciplina da graduação. Quando comparamos as respostas daqueles que utilizaram o celular (Figura 4a) com as daqueles que usaram o computador (Figura 4b), constatamos que suas intenções de uso são muito semelhantes, com uma alta inclinação ao uso da ferramenta. A única proposta para a 
(C) COBENGE

"Os desafios para formar hoje o engenheiro do amanhã"
$\mathrm{Ol}$ a $\mathrm{O3}$ de dezembro Evento On-line

qual houve divergência significativa foi a de apresentar seminários, onde percebemos uma maior disposição dos usuários de computador. Verificamos também que os usuários de computador apresentaram menor rejeição às intenções em comparação aos usuários de celular para praticamente todas as possibilidades apresentadas.

Coletamos, ainda, a opinião dos usuários quanto a diversas ferramentas de videoconferência que vêm sendo usadas no ensino remoto (Figura 5). Verificamos que a maioria dos usuários não havia assistido a aulas remotas pelo Skype, nem pelo Discord. A maioria já havia assistido a aulas remotas pelo Zoom, pelo YouTube e pelo Instagram. Constatamos que, dessas ferramentas, a que apresentou maior rejeição foi o Instagram, seguido pelo Zoom. Embora o YouTube tenha sido bem avaliado, a ferramenta que teve o maior percentual de avaliações positivas comparadas às avaliações negativas foi o Google Meet, com 97,4\% de aprovação e apenas 2,6\% de reprovação.

Figura 4 - Respostas dos participantes quanto a sua disposição de participar de cursos on-line: respostas de usuários de (a) celular e (b) computador.

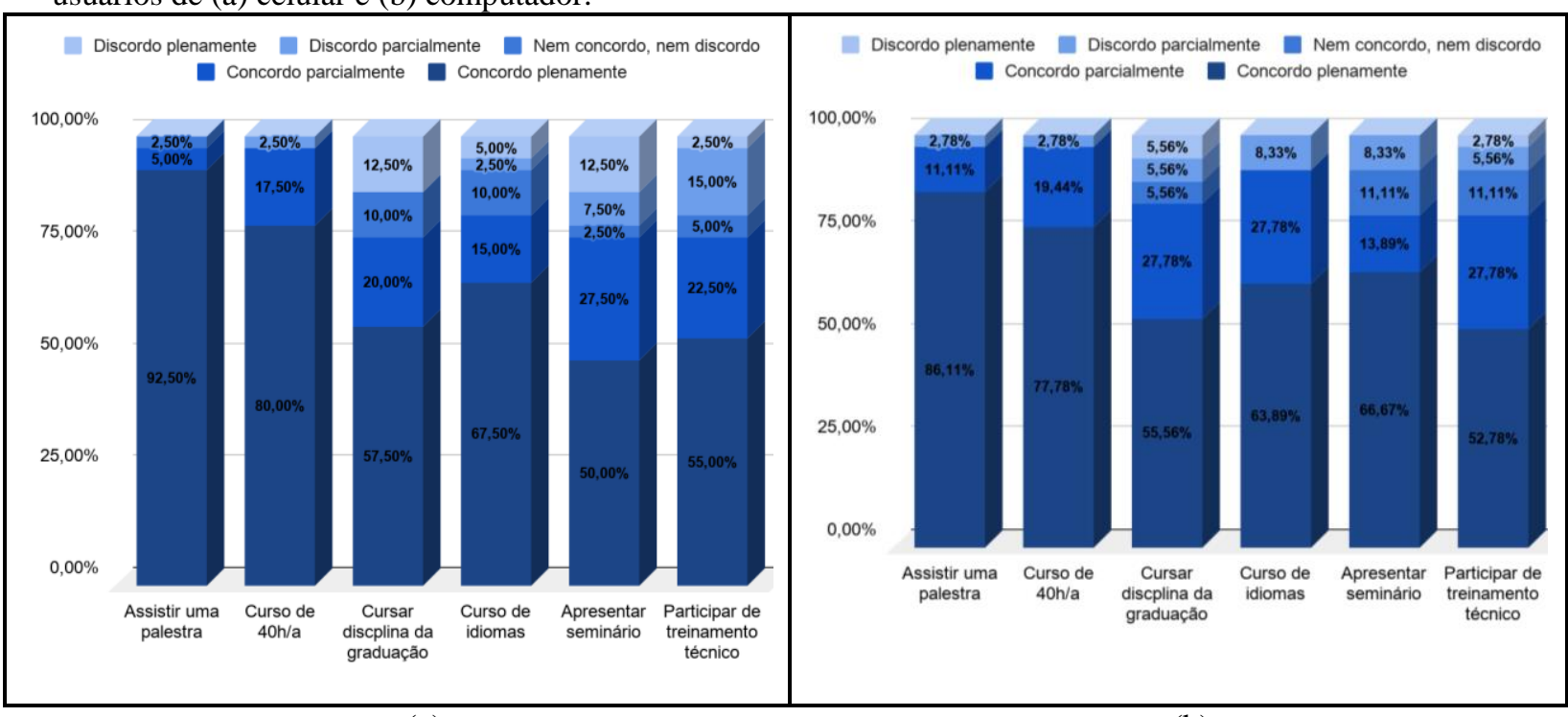

(a)

(b)

Figura 5 - Respostas dos participantes quanto ao uso de outras ferramentas usadas em aulas on-line.

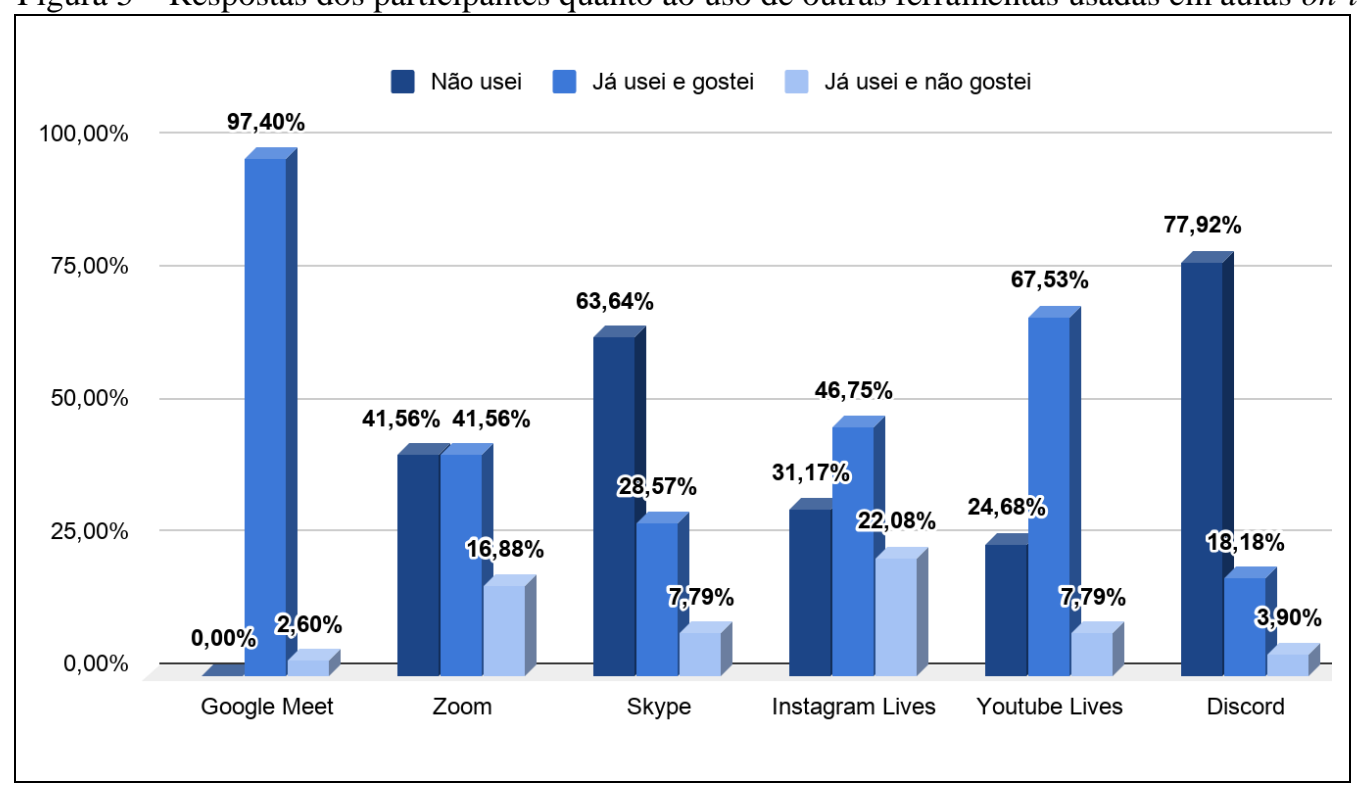


Ao questionarmos os usuários sobre seu conhecimento acerca de algumas extensões do Google Meet, percebemos que a maioria deles não conhecia as extensões e, dos poucos que as conheciam, boa parte nunca as haviam usado.

Perguntamos aos usuários se eles se sentiam incomodados com algumas situações durante uma aula remota pelo Google Meet, tais como câmeras ligadas de usuários participando apenas como ouvintes, a necessidade de ter que esperar a aprovação do moderador para adentrar a sala, dentre outras. De todos os pontos questionados, percebemos que o único que causa certo desconforto na maioria dos participantes $(50,6 \%)$ é o fato de alguns usuários que estão participando apenas como ouvintes deixarem suas câmeras ligadas durante a aula remota (Figura 6).

Figura 6 - Respostas dos participantes quanto ao incômodo provocado por limitações do Google Meet.

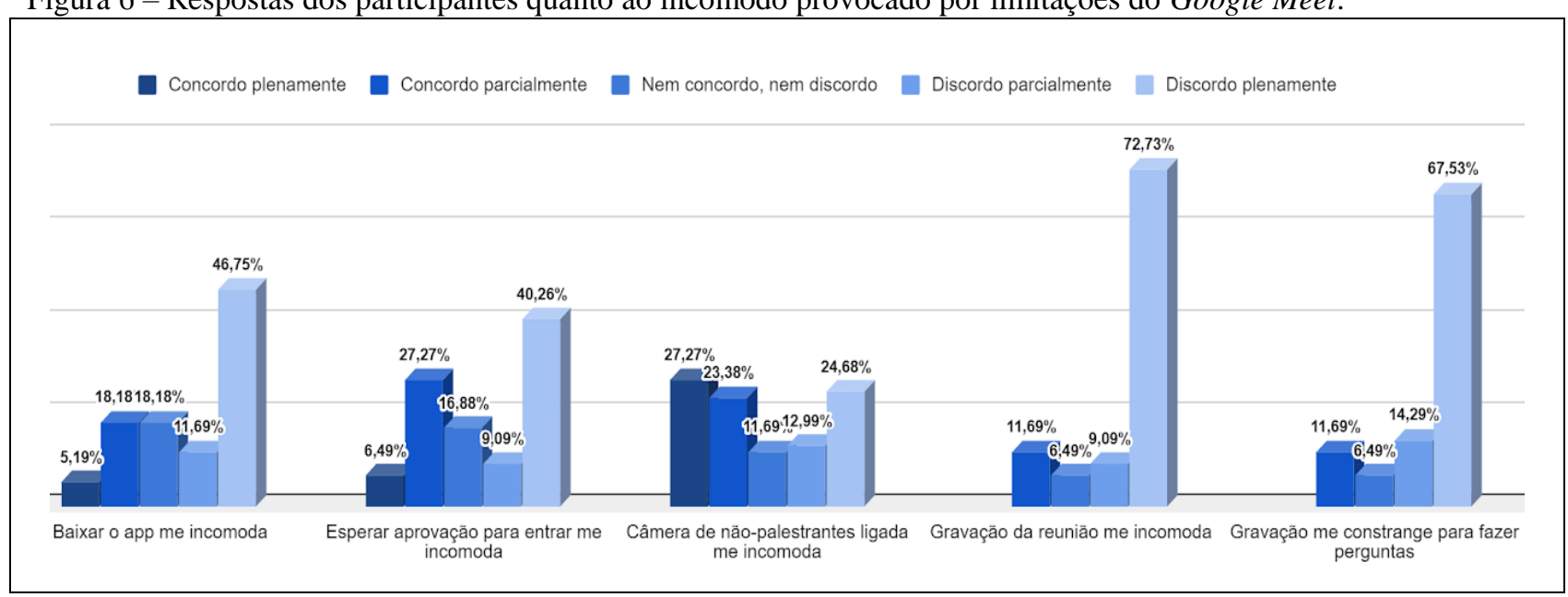

\section{CONCLUSÕES}

A partir dos resultados obtidos, constatamos que o Google Meet é uma ferramenta versátil que atende de forma satisfatória a diversas atividades e cursos que possuem distintas necessidades. Nas aulas de Libras, as câmeras dos participantes aliadas à extensão Grid View possibilitaram que todos vissem, em tempo real, os sinais uns dos outros. Nas aulas de inglês, apenas o áudio já supria a demanda de conversação, enquanto o compartilhamento de tela permitia ao professor usar um documento de texto como lousa digital. Nos minicursos, a funcionalidade de gravação das aulas foi de fundamental importância para que os alunos que perderam alguma aula ou parte dela pudessem recuperá-la, sem prejuízos. Nas palestras e mesas-redondas, a capacidade de até 250 participantes possibilitou amplo acesso aos eventos.

A plataforma foi bem avaliada tanto por aqueles que acessaram os eventos pelo computador, quanto por aqueles que usaram o smartphone, não havendo diferença significativa quanto à avaliação desses dois perfis em relação aos diferentes parâmetros avaliados.

Os participantes demonstraram disposição em participar de diversos tipos de eventos pelo Google Meet. Só houve um menor percentual de interesse para usuários de smartphones quanto a cursar disciplinas de um curso superior inteiramente pela ferramenta. Esse resultado pode ser explicado pelo fato de que, para cursar uma disciplina, geralmente há trabalhos, atividades, projetos e práticas que são de difícil execução para usuários de smartphones. Também destacamos que os respondentes avaliaram o Google Meet como superior, em relação à funcionalidade para aulas remotas, quando comparado a outras ferramentas que vêm 
sendo também bastante utilizadas, como Zoom, Skype, Instagram Live, YouTube Live e Discord.

Contudo, o Google Meet possui também algumas limitações, como a impossibilidade de o administrador desativar a câmera dos participantes ouvintes. Além disso, para participar da videochamada, o participante não precisa estar conectado a seu e-mail, de forma que é possível que pessoas mal intencionadas consigam, por meio do link de acesso, adentrar a sala e tumultuar o andamento do evento.

Como trabalhos futuros, pretendemos analisar a satisfação dos usuários do Google Meet em aulas de disciplinas de curso superior. Também pretendemos verificar, com grupo de controle e de teste, a satisfação dos usuários de duas ferramentas comparadas (Zoom e Google Meet), além de avaliar outras ferramentas digitais que podem ser integradas ao Google Meet no ensino remoto.

\section{REFERÊNCIAS}

AL-FRAIHAT, D. et al. Evaluating E-learning systems success: An empirical study. Computers in Human Behavior, v. 102, p. 67-86, 2020.

ALLSOP, S. et al. Using videoconferencing to deliver anatomy teaching to medical students on clinical placements. Translational Research in Anatomy, v. 19, p. 100059, 2020.

BOZKURT, A; SHARMA, R. C. Emergency remote teaching in a time of global crisis due to CoronaVirus pandemic. Asian Journal of Distance Education, v. 15, n. 1, p. i-vi, 2020.

BRADLEY, C. S.; JOHNSON, B. K.; DREIFUERST, K. T. Debriefing: A Place for Enthusiastic Teaching and Learning at a Distance. Clinical Simulation in Nursing, 2020.

CHICK, R. C. et al. Using technology to maintain the education of residents during the COVID-19 pandemic. Journal of Surgical Education, 2020.

CHILTON, H.; MCCRACKEN, W. New technology, changing pedagogies? Exploring the concept of remote teaching placement supervision. Higher Education Pedagogies, v. 2, n. 1, p. 116-130, 2017.

COSTA, A. R. Educação à Distância no Brasil: Concepções, histórico e bases legais. Revista Científica da FASETE, p. 69-74, 2017.

FOGAÇA, A. Google Meet ganha 3 milhões de usuários novos por dia em meio à COVID-19. Disponível em: https://tecnoblog.net/336167/google-meet-ganha-3-milhoes-deusuarios-novos-por-dia-em-meio-a-Covid-19/. Acesso em: 30 jun. 2020.

FONSECA, S. M.; MATTAR, J. Metodologias ativas aplicadas à educação a distância: revisão da literatura. Revista EDaPECI, v. 17, n. 2, p. 185-197, 2017.

G1. Coronavírus: veja a cronologia da doença no Brasil. Disponível em: https://g1.globo.com/bemestar/coronavirus/noticia/2020/04/06/coronavirus-veja-a-cronologiada-doenca-no-brasil.ghtml. Acesso em: 01 jul. 2020.

GHAZAL, S.; SAMSUDIN, Z.; ALDOWAH, H. Students' perception of synchronous courses using skype-based video conferencing. Indian Journal of Science and Technology, v. 8, n. $30,2015$.

HODGES, C. B. et al. As diferenças entre o aprendizado online e o ensino remoto de emergência. Disponível em: https://er.educause.edu/articles/2020/3/the-difference-betweenemergency-remote-teaching-and-online-learning. Acesso em: 22 jun. 2020. 
KENSKI, V. M. O desafio da educação a distância no Brasil. Revista Educação em Foco, v. 7, n. 1, p. 1-13, 2002.

MAIA, D. L.; CASTRO FILHO, J. A. E quando Skype, Facebook e Whatsapp são usados em formação de professoras que ensinam Matemática? Revista Tecnologias na Educação (TecEdu), v. 20, p. 1-20, 2017.

MURATA, Kazuya; FUJIMOTO, Takayuki. Construction of Remote Class Environment by" Low-Cost Computing" and Introduction of Class Support Application. In: Proceedings of the International Conference on Scientific Computing (CSC). 2019. p. 80-84.

MUSTAFA, E. N. E. The impact of YouTube, Skype and WhatsApp in improving EFL learners' speaking skill. International Journal of Contemporary Applied Researches, v. 5, n. 5, p. 18-31, 2018.

SCHERER, S.; BRITO, G. S. Educação a distância: possibilidades e desafios para a aprendizagem cooperativa em ambientes virtuais de aprendizagem. Educar em Revista, p. 53-77, 2014.

VAGARINHO, J. P. O que devemos ter em conta para definir corretamente os termos distance learning, e-learning e m-learning? Educar em Revista, v. 34, n. 68, p. 269-287, 2018.

\section{FEASIBILITY OF GOOGLE MEET IN REMOTE CLASSES}

Abstract: With the Covid-19 pandemic in 2020, the whole world had to adapt and deal with the situation. In education, it was not different, and several educational institutions around the world had to change the way they developed their educational activities. As a result, many educators needed to use distance-learning tools to maintain their activities. This work presents the characteristics, advantages, and disadvantages of one of these tools, Google Meet, as an audio and video communication platform used for educational purposes. We conducted this study with 77 users of the platform, who participated in different activities and courses. As a result, we detected a high level of satisfaction of these users, where $89.61 \%$ of them evaluate the interface as friendly, $96.10 \%$ consider the recording resource of the class useful, and $88.31 \%$ consider the screen-sharing an important resource. In addition, when comparing with other tools, Google Meet was the best qualified with 97.4\%, followed by YouTube Live with $67.53 \%$.

Keywords: Google Meet. Remote Teaching. Remote lessons. Distance learning. Distance teaching. 